\title{
A randomized trial of protein supplementation compared with extra fast food on the effects of resistance training to increase metabolism
}

\author{
David Hambre, Marta Vergara, Yvonne Lood, Margareta Bachrach-Lindström, \\ Torbjörn Lindström and Fredrik H Nyström
}

\section{Linköping University Post Print}

N.B.: When citing this work, cite the original article.

Original Publication:

David Hambre, Marta Vergara, Yvonne Lood, Margareta Bachrach-Lindström, Torbjörn Lindström and Fredrik H Nyström, A randomized trial of protein supplementation compared with extra fast food on the effects of resistance training to increase metabolism, 2012, Scandinavian Journal of Clinical and Laboratory Investigation, (72), 6, 471-478.

http://dx.doi.org/10.3109/00365513.2012.698021

Copyright: Informa Healthcare

http://informahealthcare.com/

Postprint available at: Linköping University Electronic Press

http://urn.kb.se/resolve?urn=urn:nbn:se:liu:diva-84890 
Original Article

Figures in black and white

Received: 28-Oct-2011

Accepted: 20-May-2012

\section{A randomized trial of protein supplementation compared with extra fast food on the effects of resistance training to increase metabolism}

\section{Running head: Resistance training increases RMR}

David Hambre $^{1}$, Marta Vergara ${ }^{1}$, Yvonne Lood ${ }^{2}$, Margareta Bachrach-Lindström ${ }^{1}$, Torbjörn Lindström ${ }^{1}$ and Fredrik H Nystrom ${ }^{1,3}$. ${ }^{1}$ Department of Medical and Health Sciences, ${ }^{2}$ Department of Forensic Genetics and Forensic Toxicology, National Board of Forensic Medicine. ${ }^{3}$ Diabetes Research Centre. Faculty of Health Sciences, Linköping University, Linköping, Sweden.

Registered at ClinicalTrials.gov: NCT01325038

Address correspondence to:

Fredrik H. Nystrom MD PhD professor

Department of Medical and Health Sciences

Linköping University

SE 58185 Linköping, Sweden

Telephone; +46101037749

Fax; +46 13145949

E-mail; fredrik.nystrom@lio.se 


\begin{abstract}
Objective To prospectively evaluate the effects of resistance training combined with increased energy intake or protein-supplementation on lean body-mass, resting metabolic-rate (RMR) and cardiovascular risk factors.
\end{abstract}

Methods Twenty-four healthy males (age 19-32 years) performed resistance exercise for 12 weeks aiming for at least 1 hour training-sessions 3 times a week. The participants were randomized to consume extra protein (33g whey protein/day) or a meal of fast-food/day (1350 kcal, 41g protein). Body-composition was measured with Dual-Energy X-ray Absorptiometry (DEXA) and RMR by indirect calorimetry. Fasting blood samples were drawn before and after the three month training-period and after 12 months.

Results The body weight increased from $75.1 \pm 6.9 \mathrm{~kg}$ to $78.7 \pm 7.2 \mathrm{~kg}$ ( $\mathrm{p}<0.0001)$, without differences between groups. RMR increased from $1787 \pm 143 \mathrm{kcal} / 24 \mathrm{~h}$ to $1954 \pm 187 \mathrm{kcal} / 24 \mathrm{~h}$ $(\mathrm{p}<0.0001, \mathrm{n}=24)$, which was more than expected from the increase in lean body-mass (increase from $59.7 \pm 4.3 \mathrm{~kg}$ to $61.8 \pm 4.1 \mathrm{~kg} \mathrm{p}=0.004$ ). Fasting serum-insulin levels increased in the fast-food group compared with the extra-protein group $(\mathrm{p}=0.03)$. ApoB increased from $0.691 \pm 0.14 \mathrm{~g} / \mathrm{L}$ to $0.768 \pm 0.17 \mathrm{~g} / \mathrm{L}, \mathrm{p}=0.004$, in the fast-food group only. Long-term follow up after 12 months showed that RMR, body weight, total fat and lean body-masses did not differ from baseline $(n=19)$.

Conclusions Resistance training for 12 weeks increased RMR and lean body-mass similarly when based on either an increased energy-intake or protein supplement. However, the increase in RMR was higher than expected from the increase in lean body-mass. Thus resistance training could potentially decrease the risk of obesity by induction of increased RMR.

Key words: cholesterol, insulin, resistance training, protein, fast-food. 


\section{Introduction}

The increasing prevalence of obesity and overweight affects more than a billion humans and has become a major health problem worldwide [1]. People with excess body weight have an increased risk to develop type 2 diabetes, dyslipidemia, hypertension and cancer [2]. In general the body weight increases when energy intake exceeds energy expenditure, although there is considerable inter-individual variation regarding the absolute weight-gain during increased energy intake [3-5]. Current strategies to lose weight usually include cutting down on caloric intake in combination with increasing physical exercise in order to accomplish a negative energy balance.

It is well known that the variation in resting metabolic rate (RMR) to a large part is determined by the amount of lean body-mass [6], i.e. muscle mass, since the muscle tissue consumes relatively large amounts of energy at rest, in particular if compared to the much less energy demanding fat tissue. Indeed, fat tissue has the main purpose to store energy in the form of triglycerides that can be released as free fatty acids and glycerol in between meals. Typically the correlation between RMR and total lean body mass gives an $r^{2}$ value of 0.9 implying that $90 \%$ of the variation in RMR is determined by the amount of muscle mass [3, 7]. Other factors that regulate RMR include thyroid hormones [8] and the sympathetic nervous system activity $[9,10]$.

The metabolic effects of insulin are mainly to increase glucose uptake by means of translocation of the GLUT4 glucose transporter in fat cells and muscle tissue and also to reduce lipolysis in fat tissue [11]. The levels of insulin increases during weight gain [4] to overcome the resistance to glucose lowering effects of insulin. Speculatively, it is possible that anabolic effects of insulin in muscle tissue, in contrast to the metabolic actions, might 
remain intact in obesity and in such case a specific resistance to the metabolic effects could potentially increase anabolism in muscle tissue as a consequence of raised insulin levels. Indeed, such an effect would be of use as the body gets heavier in obesity. Among body builders the term "bulking" refers to gaining muscle tissue by extra consumption of calories while keeping the type of exercises that are performed more or less unchanged.

Some earlier studies have demonstrated that resistance training can increase lean body mass and concomitantly elevate RMR [12-15], although this has not always been the case in both genders [12] or when studied separately in women [15, 16]. Resistance training has also been shown to reduce the decrease in resting metabolic rate during weight loss [17]. To our knowledge, however, there have been no earlier randomized trials on the effects of increased energy intake to achieve increased insulin levels during resistance training also including a long-term follow up. An effect of training to increase muscle mass, if also achieving increased metabolic rate, would make such recommendations of interest to avoid obesity in the long run.

We recruited 24 healthy males to prospectively study if resistance exercise for three months increases RMR in parallel with a presumed increase of muscle mass. The participants were also randomized to either consume extra protein or to a general increase in calories by an extra meal of fast-food per day as a pilot study of the potential modulation of the response in muscle mass by increased energy intake and presumed increases of insulin levels. The protocol also included assessment of long-term effects of the intervention by re-investigation of muscle mass and RMR after one year and potential interactions with testosterone by means of urinary steroid analyses. Our hypothesis was that resistance training would increase muscle mass leading to an increased basal metabolic rate and that this effect might be enhanced 
further by consumption of fast food by means of increased levels of the anabolic hormone insulin.

\section{Methods}

\section{Subjects}

By local advertising we recruited 24 men aged 19-32 years, as volunteers for the study. All subjects except one were medical students. The participants were free from current diseases as judged by medical check-up and history. Subjects were randomly assigned either to resistance training in combination with addition of a fast-food-based meal/day or the same kind of resistance training in combination with protein supplement.

\section{Exercise}

All participants attended a local gym (Nautilus, Linköping, Sweden) for resistance training and were asked to exercise at least 1 hour, 3 times a week. They were asked not to perform endurance or aerobic exercises except when warming-up for the resistance training. The participants followed an introduction given by instructors at the gym, whom also were available for questioning throughout the study period. Participants were asked to individually apply maximal muscle strength and there were 3-5 training sets with 8-10 repetitions in each set. The participants made notes on how often and for how long time on each occasion that they exercised.

\section{Food intake}

The group randomized to a general increase in caloric intake were instructed to eat one fastfood-based meal a day at well known fast-food restaurants with a typical composition of 1350 kcal in total, $51 \mathrm{~g}$ of fat in total (saturated fat: $17 \mathrm{~g}$ ), $41 \mathrm{~g}$ protein and $182 \mathrm{~g}$ carbohydrates. 
This daily meal was instructed to be added as extra nutrient intake, to the best of the participant ability, on top of the regular diet, in order to accomplish increased energy intake during the study. The cost for the extra food was consecutively reimbursed based on the corresponding receipts. Participants of the other group were given a 3.5 kilo supplement packaging (106 servings) of protein powder (100\% Whey protein fuel, Twinlab, American Fork, Utah, USA) with one serving (33 gram) to be consumed daily to accomplish increased intake of proteins. The participants were not given any particular instruction on when to consume the extra protein or the extra meal. No other dietary directives were given except for a general instruction not to lose weight by accomplishing negative energy balance as a consequence of the exercise. After the active 12 weeks period of the study, no specific recommendations on how to eat or exercise were given and a long-term follow up was scheduled also at 12 months after study start.

The participants completed a 7-day diet diary including weekdays and weekends, both before the start of the study and after three months of training. In the diaries they could find written information about how to report their meals. The participants were equipped with scales to accomplish this task, and food composition was analyzed as described earlier $[18,19]$ using the Dietist XP program (Kost och Näringsdata, Bromma, Sweden). Sagittal abdominal diameter (SAD) was measured with a sliding beam set square as the highest abdominal level above the upper surface of the corresponding bed.

\section{Muscle strength}

The participants warmed-up by cycling on a bicycle ergometer for five minutes and the torque of the quadriceps and hamstring muscles was then recorded using a Biodex machine (Biodex Medical Systems Inc., Ronkonkoma, NY). The participants were secured to the chair with 
body straps, and the resistance pad on the measuring arm was placed at the level of the ankle joint. Before the recording, sub-maximal familiarization repetitions were performed. Three repetitions of maximal isokinetic $60 \%$ sec knee extension and flexion were then performed and documented when using the dominant leg [20]. All the investigations were performed at baseline and within one week after the last training session, except for one participant, who for logistic reasons was followed up 13 days after the last training session.

\section{Laboratory analyses}

In order to analyze potential anabolic effects of natural anabolic hormones, urinary samples for testosterone analyses were collected as morning urine, after at least 5 hours of sleep, at baseline and at the end of the three month period. Urine-testosterone was determined by gas chromatography-mass spectrometry (7890A GC and 5975C MSD, Agilent Technologies, Santa Clara, California, USA) and sample preparation included enzymatic hydrolysis, liquidliquid extraction and derivatization, as previously described, with minor modifications [21, 22]. The concentrations of testosterone were measured by using the internal standard $d_{3}-$ testosterone. The between day precision $(\mathrm{CV})$ during one year $(\mathrm{n}=56)$ were $14.7 \%$ at $5 \mathrm{ng} / \mathrm{mL}$ and $12.2 \%$ at $100 \mathrm{ng} / \mathrm{mL}$. The limit of quantification was $1.0 \mathrm{ng} / \mathrm{mL}$ urine.

Blood for laboratory tests was drawn in the fasting state at baseline, i.e. before starting training, at the end of the training-period of the study, and at 12 months. Serum-insulin was assayed using an immunoassay method (AutoDelfia, Perkin Elmer, Linköping, Sweden). Total-cholesterol, HDL-cholesterol and triglycerides were determined by colorimetric analyses (Siemens, Liederbach, Germany) and LDL-cholesterol was calculated according to the Friedewald formula (total-cholesterol - HDL-cholesterol - $0.456 \mathrm{x}$ total triglyceride concentration). Glucose was determined by the hexokinase method (Siemens, Liederbach, 
Germany). Homeostasis model assessment (HOMA) index of insulin resistance was calculated as: glucose concentration $\mathrm{x}$ insulin concentration/22.5 [23], while the Quantitative insulin sensitivity check index (QUICKI) was calculated as: $1 /[\log ($ insulin concentration $)+$ $\log$ (glucose concentration)] [24].

\section{Muscle mass and metabolic rate}

The subjects were subjected to Dual Energy X-ray Absorptiometry (DEXA: Lunar Prodigy, GE Healthcare, Waukesha, Wisconsin, USA), for analysis of body composition. The technique for measurement of RMR has been described earlier [3] and was based on analysis of $\mathrm{CO}_{2}$ production and $\mathrm{O}_{2}$ consumption with Delta Trac equipment (SensorMedics, Yorba Linda, California, USA). The RMR was measured at least 36 hours after the previous training session in the morning in the fasting state at baseline, after one (week 4-7), 3 and 12 months. The Delta Trac equipment was calibrated ahead of each use. All anthropometric measurements during the training period of the study were done by the same investigator, $\mathrm{DH}$, while follow up was conducted by MV.

\section{Statistics}

Statistical calculations were done with PASW 18.0 software (SPSS Inc. Chicago, IL, USA). Comparisons within and between groups were done with Student's paired and unpaired 2tailed t-test or as stated in the results section. Mean values and standard deviations are given, unless otherwise stated. Statistical significance was considered at the 5\% level $(p \leq 0.05)$. Linear correlations were done according to Pearson and analysis of RMR and lean body mass over time (three time points) was calculated with ANOVA/repeated measures. The SD of the difference of pair-wise RMR registrations divided by the mean value of the registrations (the 
precision) according to an earlier investigation by us [3] was $3 \%$ which gave $80 \%$ power to detect a $5 \%$ change of RMR within any of the two groups.

\section{Ethics}

The study was approved by the Regional Ethics Committee of Linköping and performed in accordance with the Declaration of Helsinki. Written informed consent was obtained from all participating subjects.

\section{Results}

All 24 recruited participants completed the trial during the spring of 2008. None of the participants had been performing resistance training during the previous 6 months, 4 had never earlier practiced resistance training. During the 12 week study period the participants exercised on $32 \pm 5$ occasions with no difference between groups (extra protein: $31 \pm 2$ occasions, extra meal: $34 \pm 6$ occasions, $\mathrm{p}=0.16$ ). The total time spent in the gym was also similar in the groups (extra protein: $1982 \pm 489$ minutes, extra meal: $2324 \pm 489$ minutes, $\mathrm{p}=$ 0.10). One participant was using snuff (moist tobacco), and one subject was a smoker. The recruited participants gained on average $3.6 \pm 2.8 \mathrm{~kg}$ in body weight with no statistical difference between the two groups (Table I). Levels of ApoB increased in the extra meal group only, and levels of ApoB/ApoA1-ratio increased in both groups (Table I). The marker of insulin resistance, HOMA, increased and QUICKI, index of insulin sensitivity, decreased in the extra meal group, and levels of fasting insulin also increased more in the group with increased energy intake (all $\mathrm{p}$ for changes between groups $<0.05$, see Table I).

Table II shows changes in macro-nutrient intake, body composition, muscle strength, and testosterone-epitestosterone-ratio in urine following the intervention. The increases in lean 
body-mass and muscle strength were similar in both groups while the amount of increase in body fat was statistically significant only in the extra meal group. However, the difference was not statistically significant between the groups (Table II). Figure 1 illustrates changes in RMR during the entire study-period of 12 months. RMR did not differ between groups at baseline (extra meal: $1782 \pm 121 \mathrm{kcal} / 24 \mathrm{~h}$, extra protein $1791 \pm 168 \mathrm{kcal} / 24 \mathrm{~h} \mathrm{p}=0.9)$. RMR was increased in both groups after one month of training (extra meal: $1992 \pm 119 \mathrm{kcal} / 24 \mathrm{~h}$, extra protein $2056 \pm 232 \mathrm{kcal} / 24 \mathrm{~h}, \mathrm{p}<0.0001$ compared with baseline for both). The levels were higher at three months compared with baseline in both groups (extra meal: 1959 \pm 154 $\mathrm{kcal} / 24 \mathrm{~h}$, extra protein $1948 \pm 221 \mathrm{kcal} / 24 \mathrm{~h}, \mathrm{p}=0.003$ and $\mathrm{p}<0.0001$ compared with baseline, respectively). The change in RMR from baseline to the measurements at week 4 and 12 were similar in both groups ( $\mathrm{p}=0.27$ by ANOVA, repeated measures). The numeric decline in RMR between the measurement at 1 month to the end of the training period was not statistically significant in the extra meal group (change from week 4 to week 12 in the extra meal group: $-32.2 \pm 94 \mathrm{kcal} / 24 \mathrm{~h}, \mathrm{p}=0.22$, in the extra protein group: $-108 \pm 109 \mathrm{kcal} / 24 \mathrm{~h}, \mathrm{p}=$ 0.005). Body weight at 4 weeks was $76.9 \pm 5.8 \mathrm{~kg}$ in the extra meal group and corresponding value in the group eating extra protein was $77.7 \pm 8.0 \mathrm{~kg}$. The change in RMR from week 4 to week 12 was positively correlated with the number of training sessions $(r=0.58, p=0.003)$, i.e. suggesting that the participants who trained most frequently generally increased the RMR from week 4 to 12 . 

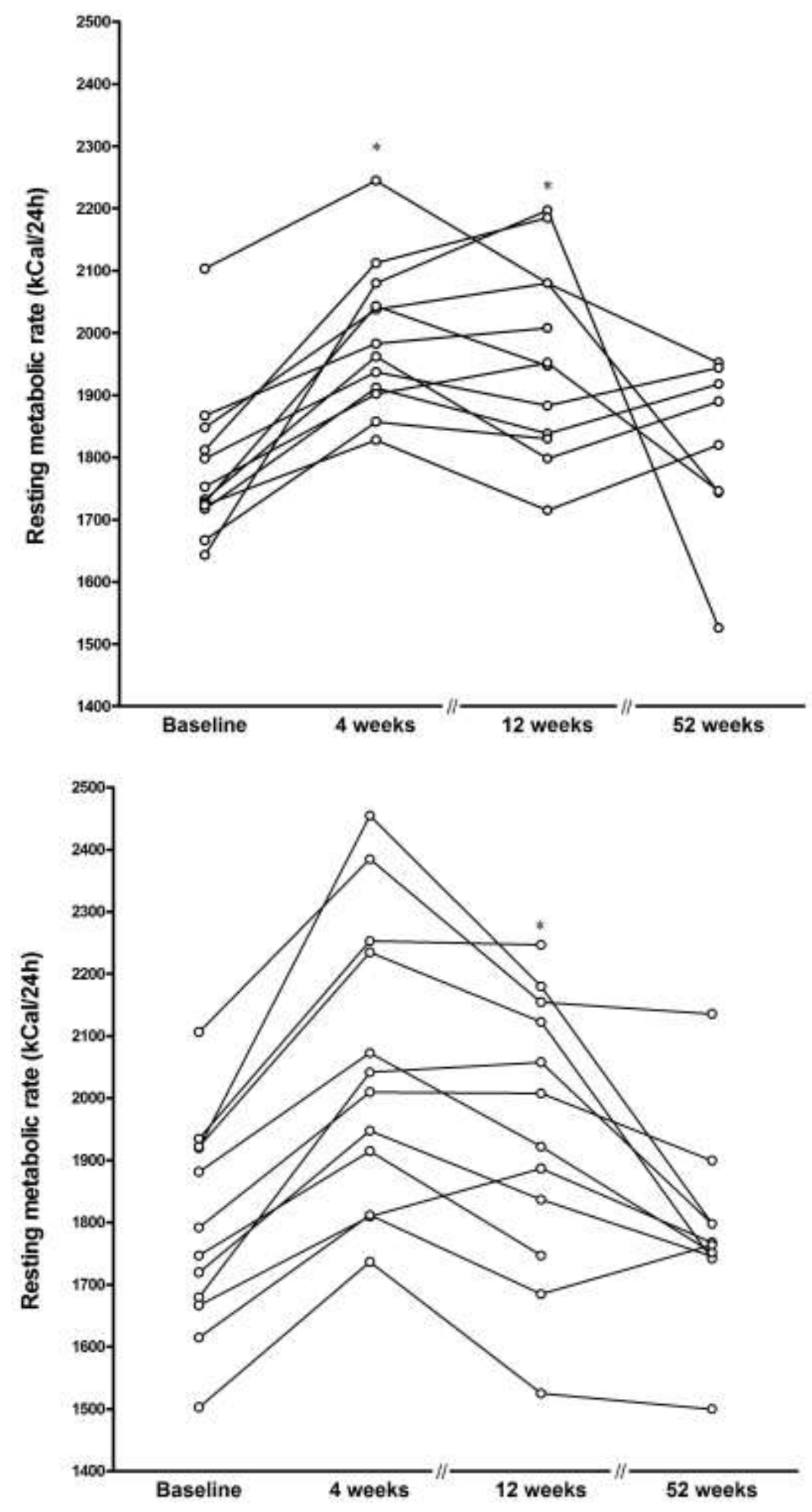

Figure 1 Change in resting metabolic rate. Individual levels of resting metabolic rate (Kcal/24h) in the participants from baseline to the long-term follow-up at 12 months in the two groups, a extra meal, b extra protein. *Denotes statistical difference compared with baseline within the group. The changes in levels of RMR from baseline to that at 1 and 3 months were similar in both groups ( $\mathrm{p}=0.27$ by analysis of repeated measures). 
In all participants there was a correlation between the number of training sessions and increase in RMR during the study (linear regression, $r=0.71, p<0.0001$ ), while there was a trend for a similar relationship with change of lean body mass and number of training sessions $(\mathrm{r}=0.39, \mathrm{p}=0.062)$. The level of the anabolic hormone testosterone, measured as the testosterone/epitestosterone-ratio in urine, was unchanged by the intervention (Table II) and the level at baseline was unrelated to the increase in muscle mass or RMR (all $p>0.5$ ). There was no correlation between the change in intake of protein and the corresponding change of daily intake of calories $(\mathrm{r}=0.20, \mathrm{p}=0.4)$.

There was no correlation between change of RMR and change of lean body mass in linear regression analysis in the total material at three months $(\mathrm{r}=0.1, \mathrm{p}=0.8)$. However, RMR per $\mathrm{kg}$ lean body mass was higher after 3 months of exercise (total material before $30.0 \pm 2.4$ $\mathrm{kcal} / \mathrm{kg}$, after: $31.6 \pm 2.2 \mathrm{kcal} / \mathrm{kg}, \mathrm{p}=0.003$ in paired t-test). This increase in RMR per kg lean body mass was related to the increase in body fat content (linear regression analysis $r=0.42$, $\mathrm{p}=0.04)$. The change in RMR per kg lean body mass was independent of protein or caloric intake (all $\mathrm{p}>0.5$ ). Nineteen of the 24 participants were available for long-term follow up after 12 months and at this investigation, RMR per kg lean body mass did not differ from that at baseline (baseline 30.3 \pm 2.6 , long-term: $30.5 \pm 2.0 \mathrm{kcal} / \mathrm{kg}, \mathrm{p}=0.6, \mathrm{n}=19$ ). There was a statistically significant correlation between the change of RMR with the corresponding change in lean body mass from baseline to results after one year $(r=0.70, p=0.001, n=19)$.

Of the 10 subjects that had earlier been randomized to extra protein, two claimed that they still performed resistance training 1-2 times/week while one subject exercised 3-4 times/week. Corresponding figures for the fast-food group were 6 subjects exercising 1-2 times/week after one year. RMR, body weight, total fat and lean body masses had returned to baseline levels at 
long-term follow up (see Table III). Those nine subjects that reported that they performed resistance training after one year also showed RMR and muscle mass at similar levels as at baseline ( $p>0.5$ for both comparisons).

\section{Discussion}

Our study showed that three months of resistance exercise increased RMR and lean body mass. Statistical analyses suggested that part of the increase in RMR at three months was a consequence of an increase in the RMR per kg of lean body mass, i.e. an increased energy requirement per weight unit of muscle tissue at rest. The absolute increase in RMR was similar in both groups after three months, which suggests that it was independent of an increased amount of intake of calories from fat and carbohydrates as was accomplished in the extra meal group. At long-term follow up RMR per kg of lean body mass did not differ from that at baseline, and at this time point the change from baseline in lean body mass correlated strongly with the corresponding change in RMR. This suggests that the variation in RMR is indeed related to change in muscle tissue mass in long-term.

Although we did find higher levels of insulin in the group randomized to fast-food, this was not accompanied by a more pronounced accumulation of muscle tissue. This suggests that potential anabolic effects of insulin do not affect the RMR or muscle mass per se. However, our study might have been underpowered to study such effects, and the interpretation and analysis of the data showed that the number of training sessions contributed to the increase in RMR, a phenomenon that might have reduced the ability to detect effects of other variables that also could have contributed to change in muscle tissue. However, our main goal was to study prospectively the potential effect of resistance training for a relatively short time period, 
so we encouraged all participants to exercise as much as possible rather than restraining all participants to perform the same amount of exercise. Furthermore we believe that introducing strict training schedules with control of time and effort spent by the participants would make findings of less clinical interest since such resources are unlikely to be present in the long term. It is noteworthy that the changes in insulin and C-peptide levels were numerically small compared with spontaneous variation in a population in which fasting insulin levels and insulin sensitivity can vary 10-fold [25]. Accordingly our study should be viewed upon as a pilot-study of the importance of insulin acting as an important anabolic factor in building muscle tissue. Larger studies would be needed to better test this hypothesis since the lack of a positive finding in our study suggests that any such effect is not very strong, at least not in the cohort of young and healthy men as in our trial. Furthermore, the group that was randomized to extra intake of fast food not only tended to gain more fat tissue, but displayed both reduced insulin sensitivity and higher ApoB levels, despite being more fit in the sense of gaining muscle strength, and these are effects that are unbeneficial regarding cardiovascular risk in the long term.

Our study was performed in healthy young males which might reduce the relevance of our findings for subjects in general. However, the time period for the resistance exercise was also limited and, in particular since we found that the number of training sessions related positively with the increase in RMR, it is highly conceivable that prolonged training periods would have induced stronger effects.

In order to study temporal effects in RMR, and also to give feedback to the participants, we measured RMR and body weight at one month in both groups. Somewhat surprisingly we found that many participants had numerically higher levels of RMR at this time point than at 
the end of the training-period. Body weight, which was also recorded at this occasion, was higher after three months than at this time point which makes it unlikely that the temporary increase in RMR seen in many of the participants was an effect of the increased energy intake. However, exact mechanisms behind this increase in RMR after only one month could unfortunately not be studied since we only examined weight and RMR at this time point, as the major aim of the study was to investigate the studied parameters after three months and at one year. One might speculate that the extra pronounced increase in RMR at the recording at 4 weeks was related to more strenuous training in some of the participants in the early phase of the trial. This would be in line with the finding of a positive correlation between the number of total training sessions and the change in RMR between week 4 and after 3 months.

RMR per kg muscle tissue increased after 3 months and at this time point RMR was also higher than at baseline. An increased energy expenditure in muscle has earlier been found to be correlated with amount of fat tissue [26], which was in line with our findings of a correlation with the increase in body fat content. It has also been suggested that resistance training increases sympathetic nervous system activity, which positively affects RMR, as has earlier been suggested to occur in older men [14], but no such measurements were part of our study protocol.

After one year RMR and muscle mass were similar as at baseline in the total group suggesting that to accomplish a more permanent increase in RMR by resistance training it is required that the exercise activities become routine in every-day life. Detraining is well known to cause reduction of muscle mass $[27,28]$, but we had anticipated that several of these healthy young individuals might change training habits inspired by the study and hence that potentially some part of the increase in muscle mass would have remained after 1 year. Indeed, almost half of 
the participants reported that they performed regular resistance training after one year, but apparently this was not intense enough to preserve the initial increase in muscle mass and RMR in this sub-group. Also it should be pointed out that regular exercise induces increased caloric expenditure that allows a higher energy intake. However, it should be pointed out that if the habit to perform regular resistance training ceases, a parallel reduction of caloric intake should also be undertaken to avoid that obesity develops by mismatch of energy intake and energy expenditure in the long run.

In conclusion we showed that it was feasible to increase RMR by three months of resistance exercise and that the increase was dependent on both an increase in muscle mass and a higher resting metabolic rate per $\mathrm{kg}$ of muscle tissue. However, it was equally efficient to combine the training with an increase of intake of protein as compared with a more general intake of calories in order to increase the RMR. Indeed such generally increased caloric intake in our study, based on fast food, was linked to both reduced insulin sensitivity and to higher ApoB levels, effects that are unbeneficial for long term cardiovascular health. However, resistance training with intake of extra protein, or a more general increase of caloric intake, could be helpful to avoid obesity, if performed regularly, by induction of increased RMR. Indeed, almost half of the participants that were available for long term follow up performed resistance training regularly.

\section{Funding}

The study was supported by University Hospital of Linkoping Research Funds, Linkoping University, Gamla Tjänarinnor, Medical Research Council of Southeast Sweden and the Diabetes Research Centre of Linkoping University. 


\section{Conflicts of interests}

The funders had no role in study design, data collection and analysis, decision to publish, or preparation of the manuscript. 


\section{References}

[1] Eckel, R H, Grundy, S M, and Zimmet, P Z. The metabolic syndrome. Lancet 2005;365:1415-28.

[2] Haslam, D W, and James, W P. Obesity. Lancet 2005;366:1197-209.

[3] Claesson, A L, Holm, G, Ernersson, A, Lindstrom, T, and Nystrom, F H. Two weeks of overfeeding with candy, but not peanuts, increases insulin levels and body weight. Scand J Clin Lab Invest 2009;69:598-605.

[4] Erlingsson, S, Herard, S, Dahlqvist Leinhard, O, Lindstrom, T, Lanne, T, Borga, M, and Nystrom, F H. Men develop more intraabdominal obesity and signs of the metabolic syndrome after hyperalimentation than women. Metabolism 2009;58:9951001.

[5] Joosen, A M, and Westerterp, K R. Energy expenditure during overfeeding. Nutr Metab (Lond) 2006;3:25.

[6] Wilson, M M, and Morley, J E. Invited review: Aging and energy balance. J Appl Physiol 2003;95:1728-36.

[7] de Luis, D A, Aller, R, Izaola, O, Gonzalez Sagrado, M, and Conde, R. Resting energy expenditure, cardiovascular risk factors and insulin resistance in obese patients. Ann Nutr Metab 2005;49:381-5.

[8] Moreno, M, Lombardi, A, Beneduce, L, Silvestri, E, Pinna, G, Goglia, F, and Lanni, A. Are the effects of $\mathrm{T} 3$ on resting metabolic rate in euthyroid rats entirely caused by T3 itself? Endocrinology 2002;143:504-10.

[9] Christin, L, Ravussin, E, Bogardus, C, and Howard, B V. The effect of propranolol on free fatty acid mobilization and resting metabolic rate. Metabolism 1989;38:439-44. 
[10] Ravussin, E. Low resting metabolic rate as a risk factor for weight gain: role of the sympathetic nervous system. Int J Obes Relat Metab Disord 1995;19 Suppl 7:S8-S9.

[11] Nystrom, F H, and Quon, M J. Insulin signalling: metabolic pathways and mechanisms for specificity. Cell Signal 1999;11:563-74.

[12] Broeder, C E, Burrhus, K A, Svanevik, L S, and Wilmore, J H. The effects of either high-intensity resistance or endurance training on resting metabolic rate. Am J Clin Nutr 1992;55:802-10.

[13] Dolezal, B A, and Potteiger, J A. Concurrent resistance and endurance training influence basal metabolic rate in nondieting individuals. J Appl Physiol 1998;85:695700.

[14] Pratley, R, Nicklas, B, Rubin, M, Miller, J, Smith, A, Smith, M, Hurley, B, and Goldberg, A. Strength training increases resting metabolic rate and norepinephrine levels in healthy 50- to 65-yr-old men. J Appl Physiol 1994;76:133-7.

[15] Lemmer, J T, Ivey, F M, Ryan, A S, Martel, G F, Hurlbut, D E, Metter, J E, Fozard, J L, Fleg, J L, and Hurley, B F. Effect of strength training on resting metabolic rate and physical activity: age and gender comparisons. Med Sci Sports Exerc 2001;33:532-41.

[16] Taaffe, D R, Pruitt, L, Reim, J, Butterfield, G, and Marcus, R. Effect of sustained resistance training on basal metabolic rate in older women. J Am Geriatr Soc 1995;43:465-71.

[17] Bryner, R W, Ullrich, I H, Sauers, J, Donley, D, Hornsby, G, Kolar, M, and Yeater, R. Effects of resistance vs. aerobic training combined with an 800 calorie liquid diet on lean body mass and resting metabolic rate. J Am Coll Nutr 1999;18:115-21.

[18] Astrand, O, Carlsson, M, Nilsson, I, Lindstrom, T, Borga, M, and Nystrom, F H. Weight gain by hyperalimentation elevates C-reactive protein levels but does not 
affect circulating levels of adiponectin or resistin in healthy subjects. Eur J Endocrinol 2010;163:879-85.

[19] Ernersson, A, Nystrom, F H, and Lindstrom, T. Long-term increase of fat mass after a four week intervention with fast food based hyper-alimentation and limitation of physical activity. Nutr Metab (Lond) 2010;7:68.

[20] Pincivero, D M, Lephart, S M, and Karunakara, R A. Reliability and precision of isokinetic strength and muscular endurance for the quadriceps and hamstrings. Int $\mathbf{J}$ Sports Med 1997;18:113-7.

[21] Segura, J, Pascual, J A, Ventura, R, Ustaran, J I, Cuevas, A, and Gonzalez, R. International cooperation in analytical chemistry: experience of antidoping control at the XI Pan American Games. Clin Chem 1993;39:836-45.

[22] Donike, M, Ueki, M, Kuroda, Y, Geyer, H, Nolteernsting, E, Rauth, S, Schanzer, W, Schindler, U, Volker, E, and Fujisaki, M. Detection of dihydrotestosterone (DHT) doping: alterations in the steroid profile and reference ranges for DHT and its 5 alphametabolites. J Sports Med Phys Fitness 1995;35:235-50.

[23] Bonora, E, Targher, G, Alberiche, M, Bonadonna, R C, Saggiani, F, Zenere, M B, Monauni, T, and Muggeo, M. Homeostasis model assessment closely mirrors the glucose clamp technique in the assessment of insulin sensitivity: studies in subjects with various degrees of glucose tolerance and insulin sensitivity. Diabetes Care $2000 ; 23: 57-63$

[24] Katz, A, Nambi, S S, Mather, K, Baron, A D, Follmann, D A, Sullivan, G, and Quon, M J. Quantitative insulin sensitivity check index: a simple, accurate method for assessing insulin sensitivity in humans. J Clin Endocrinol Metab 2000;85:2402-10.

[25] Lind, L, Berne, C, and Lithell, H. Prevalence of insulin resistance in essential hypertension. J Hypertens 1995;13:1457-62. 
[26] Jorgensen, J O, Vahl, N, Dall, R, and Christiansen, J S. Resting metabolic rate in healthy adults: relation to growth hormone status and leptin levels. Metabolism 1998;47:1134-9.

[27] Ivey, F M, Roth, S M, Ferrell, R E, Tracy, B L, Lemmer, J T, Hurlbut, D E, Martel, G F, Siegel, E L, Fozard, J L, Jeffrey Metter, E, Fleg, J L, and Hurley, B F. Effects of age, gender, and myostatin genotype on the hypertrophic response to heavy resistance strength training. J Gerontol A Biol Sci Med Sci 2000;55:M641-8.

[28] Vandervoort, A A. Effects of ageing on human neuromuscular function: implications for exercise. Can J Sport Sci 1992;17:178-84. 
Table I

Laboratory variables and body weight before and after three months of resistance exercise.

\begin{tabular}{|c|c|c|c|c|c|c|c|}
\hline Variable & Extra protein & After & $\begin{array}{l}\text { P for } \\
\text { change } \\
\text { within } \\
\text { group }\end{array}$ & $\begin{array}{l}\text { Extra } \\
\text { meal }\end{array}$ & After & $\begin{array}{l}\text { P for } \\
\text { change } \\
\text { within } \\
\text { group }\end{array}$ & $\begin{array}{l}\mathrm{P} \text { for } \\
\text { difference } \\
\text { in changes } \\
\text { between } \\
\text { groups }\end{array}$ \\
\hline Age (years) & $24.2(3.7)$ & N/A & N/A & $23.2(3.4)$ & N/A & N/A & N/A \\
\hline Weight $(\mathrm{kg})$ & $75.3(7.9)$ & $78.4(8.0)$ & 0.02 & $74.9(6.1)$ & $79.0(6.7)$ & 0.001 & 0.4 \\
\hline BMI $\left(\mathrm{kg} / \mathrm{m}^{2}\right)$ & $22.6(2.5)$ & $23.5(2.6)$ & 0.02 & $22.3(1.9)$ & $23.5(2.2)$ & 0.001 & 0.4 \\
\hline $\mathrm{SAD}(\mathrm{cm})$ & $19.8(1.6)$ & $19.7(1.5)$ & 0.7 & $20.2(1.0)$ & $20.3(1.3)$ & 0.6 & 0.5 \\
\hline S-Tot-chol. (mmol/L) & $4.34(0.89)$ & $4.32(1.0)$ & 0.9 & $3.97(0.64)$ & $4.27(0.85)$ & 0.033 & 0.11 \\
\hline S-LDL-chol. (mmol/L) & $2.66(0.79)$ & $2.64(0.88)$ & 0.9 & $2.25(0.59)$ & $2.63(0.70)$ & 0.070 & 0.093 \\
\hline S-HDL-chol. (mmol/L) & $1.24(0.24)$ & $1.25(0.24)$ & 0.9 & $1.20(0.25)$ & $1.31(0.28)$ & 0.081 & 0.12 \\
\hline S-Triglycerides $(\mathrm{mmol} / \mathrm{L})$ & $0.93(0.37)$ & $0.93(0.46)$ & 1 & $0.72(0.23)$ & $0.71(0.31)$ & 0.9 & 0.9 \\
\hline S-ApoB (g/L) & $0.761(0.20)$ & $0.797(0.21)$ & 0.24 & $0.691(0.14)$ & $0.768(0.17)$ & 0.004 & 0.27 \\
\hline S-ApoA1 (g/L) & $1.22(0.17)$ & $1.17(0.14)$ & 0.13 & $1.16(0.15)$ & $1.19(0.12)$ & 0.4 & 0.087 \\
\hline S-ApoB/ApoA1 & $0.638(0.21)$ & $0.688(0.19)$ & 0.035 & $0.600(0.12)$ & $0.644(0.13)$ & 0.018 & 0.8 \\
\hline FS-glucose $(\mathrm{mmol} / \mathrm{L})$ & $4.96(0.36)$ & $5.18(0.19)$ & 0.034 & $4.98(0.25)$ & $5.41(0.21)$ & $<0.0001$ & 0.096 \\
\hline FS-insulin (pmol/L) & $32.2(21)$ & $25.1(11)$ & 0.19 & $25.2(6.5)$ & $31.7(10)$ & 0.055 & 0.033 \\
\hline FS-C-peptide (nmol/L) & $0.48(0.23)$ & $0.43(0.15)$ & 0.26 & $0.42(0.095)$ & $0.49(0.13)$ & 0.025 & 0.026 \\
\hline HOMA & $1.06(0.78)$ & $0.834(0.36)$ & 0.26 & $0.807(0.22)$ & $1.10(0.36)$ & 0.020 & 0.026 \\
\hline QUICKI & $0.296(0.021)$ & $0.301(0.017)$ & 0.45 & $0.300(0.010)$ & $0.289(0.014)$ & 0.017 & 0.047 \\
\hline S-Creatinine $(\mu \mathrm{mol} / \mathrm{L})$ & $80.4(9.7)$ & $85.5(9.5)$ & 0.029 & $80.1(12)$ & $78.2(14)$ & 0.3 & 0.016 \\
\hline $\begin{array}{l}\text { Urine-testosterone/ } \\
\text { epitestosterone-ratio }\end{array}$ & $1.20(0.91)$ & $0.982(0.79)$ & 0.3 & $1.71(1.8)$ & $2.00(2.6)$ & 0.3 & 0.16 \\
\hline
\end{tabular}


Abbreviations: Tot., total; BMI, body mass index; SAD, sagittal abdominal diameter. Homeostasis model assessment (HOMA) index of insulin resistance was calculated as: glucose concentration $\mathrm{x}$ insulin concentration/22.5, while the Quantitative insulin sensitivity check index (QUICKI) was calculated as: 1/[log (insulin concentration) + log (glucose concentration)]. 
Table II

Resting metabolic rate, intake of macro nutrients, leg strength, body composition and testosterone/epitestosterone in urine before and after three months of resistance exercise.

\begin{tabular}{|l|l|l|l|l|l|l|}
\hline Variable & $\begin{array}{l}\text { Extra } \\
\text { protein }\end{array}$ & & $\begin{array}{l}\text { P for } \\
\text { changes } \\
\text { within } \\
\text { group } \\
\text { Before }\end{array}$ & After & $\begin{array}{l}\text { Extra } \\
\text { meal } \\
\text { changes } \\
\text { within } \\
\text { group } \\
\text { difference } \\
\text { changes } \\
\text { between } \\
\text { groups }\end{array}$ \\
\hline RMR (kcal/24h) & $1791(168)$ & $1948(221)$ & 0.001 & $1782(121)$ & $1959(154)$ & 0.003 \\
\hline Protein intake (g/day) & $95.9(24)$ & $140(29)$ & $<0.0001$ & $101(20)$ & $116(17)$ & 0.049 \\
\hline Total fat intake (g/day) & $91.3(25)$ & $92.1(27)$ & 0.072 & $97.7(31)$ & $121(19)$ & 0.007 \\
\hline Carbohydr. intake (g/day)* & $283(65)$ & $295(60)$ & 0.4 & $322(91)$ & $410(83)$ & $<0.0001$ \\
\hline Caloric intake (kcal/day) & $2407(475)$ & $2628(464)$ & 0.007 & $2687(633)$ & $3277(434)$ & 0.001 \\
\hline Strength quadriceps (NM) & $252(36)$ & $272(36)$ & 0.010 & $215(34)$ & $246(32)$ & 0.001 \\
\hline Strength hamstrings (NM) & $131(26)$ & $146(24)$ & 0.001 & $133(17)$ & $154(20)$ & 0.002 \\
\hline Total body fat (kg) & $13.6(6.6)$ & $14.6(6.4)$ & 0.072 & $11.4(5.1)$ & $13.2(4.6)$ & 0.028 \\
\hline Total fat free mass (kg) & $58.6(5.2)$ & $60.7(4.6)$ & 0.003 & $60.7(3.1)$ & $62.8(3.5)$ & $<0.001$ \\
\hline
\end{tabular}

Abbreviations: RMR, Resting metabolic rate; Carbohydr., carbohydrate; circ., circumference. ${ }^{*}$ Carbohydrate intake includes saccharides.

Data on urine analyses was missing in one subject of the extra protein group at the end of the study. 
Table III

Long term follow-up at 12 months in 19 subjects compared with corresponding baseline levels of the variables in the same subjects.

\begin{tabular}{|l|l|l|l|l|l|l|}
\hline Variable & Extra protein & & $\begin{array}{l}\text { P for } \\
\text { changes } \\
\text { within } \\
\text { group }\end{array}$ & $\begin{array}{l}\text { Extra } \\
\text { meal }\end{array}$ & & $\begin{array}{l}\text { P for } \\
\text { changes } \\
\text { within } \\
\text { group }\end{array}$ \\
& Before & After & & Before & After & \\
\hline Weight $(\mathrm{kg})$ & $74.9(6.6)$ & $77.0(6.4)$ & 0.10 & $74.5(6.5)$ & $74.7(5.7)$ & 0.88 \\
\hline S-Tot.-chol. (mmol/L) & $4.39(0.96)$ & $4.90(0.96)$ & 0.015 & $3.78(0.58)$ & $4.00(0.62)$ & 0.28 \\
\hline S-LDL-chol. (mmol/L) & $2.68(0.86)$ & $3.01(0.92)$ & 0.046 & $2.30(0.58)$ & $2.34(0.55)$ & 0.82 \\
\hline S-HDL-chol. (mmol/L) & $1.28(0.25)$ & $1.44(0.33)$ & 0.003 & $1.11(0.15)$ & $1.23(0.25)$ & 0.11 \\
\hline S-Triglycerides (mmol/L) & $0.93(0.38)$ & $1.00(0.47)$ & 0.44 & $0.78(0.23)$ & $0.97(0.36)$ & 0.050 \\
\hline S-ApoB (g/L) & $0.756(0.23)$ & $0.907(0.22)$ & 0.001 & $0.655(0.14)$ & $0.725(0.14)$ & 0.087 \\
\hline S-ApoA1 (g/L) & $1.23(0.18)$ & $1.29(0.22)$ & 0.32 & $1.12(0.15)$ & $1.18(0.15)$ & 0.22 \\
\hline S-ApoB/ApoA1 & $0.631(0.24)$ & $0.718(0.22)$ & 0.014 & $0.592(0.14)$ & $0.621(0.12)$ & 0.12 \\
\hline RMR (kcal/24h) & $1780(179)$ & $1790(157)$ & 0.80 & $1790(140)$ & $1818(144)$ & 0.68 \\
\hline Total body fat $(\mathrm{kg})$ & $13.6(5.6)$ & $14.9(4.1)$ & 0.21 & $11.4(5.3)$ & $10.9(4.2)$ & 0.46 \\
\hline Total lean mass $(\mathrm{kg})$ & $58.3(5.7)$ & $58.8(4.9)$ & 0.58 & $60.3(2.9)$ & $60.6(3.7)$ & 0.78 \\
\hline
\end{tabular}

Abbreviations: Tot, total; chol. cholesterol; RMR, Resting metabolic rate 